\title{
Health insurance benefit package in Iran: a qualitative policy process analysis
}

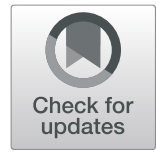

\author{
Efat Mohamadi ${ }^{1}$, Amirhossein Takian 1,2,3, Alireza Olyaeemanesh 1,4* ${ }^{1,}$ Arash Rashidian ${ }^{2,5}$, Ali Hassanzadeh ${ }^{6}$, \\ Moaven Razavi ${ }^{7}$ and Sadegh Ghazanfari ${ }^{2}$
}

\begin{abstract}
Background: Insufficient transparency in prioritization of health services, multiple health insurance organizations with various and not-aligned policies, plus limited resources to provide comprehensive health coverage are among the challenges to design appropriate Health Insurance Benefit Package (HIBP) in Iran. This study aims to analyze Policy Process of Health Insurance Benefit Package in Iran.

Method: Data were collected through semi-structured interviews with 25 experts, plus document analysis and observation, from February 2014 until October 2016. Using both deductive and inductive approaches, two independent researchers conducted data content analysis. We used MAXQDA.11 software for data management.

Results: We identified 10 main themes, plus 81 sub-themes related to development and implementation of HIBP. These included: lack of transparent criteria for inclusion of services within HIBP, inadequate use of scientific evidence to determine the HIBP, lack of evaluation systems, and weak decision-making process. We propose 11 solutions and 25 policy options to improve the situation.

Conclusion: The design and implementation of HIBP did not follow an evidence-based and logical algorithm in Iran. Rather, political and financial influences at the macro level determined the decisions. This is rooted in social, cultural, and economic norms in the country, whereby political and economic factors had the greatest impact on the implementation of HIBP. To define a cost-effective HIBP in Iran, it is pivotal to develop transparent and evidence-based guidelines about the processes and the stewardship of HIBP, which are in line with upstream policies and societal characteristics. In addition, the possible conflict of interests and its harms should be minimized in advance.
\end{abstract}

Keywords: Benefit package, Policy process analysis, Health insurance, Iran

\section{Background}

Health Insurance Benefit Package (HIBP) are the healthcare services covered by the government. Health systems use various priority setting mechanisms to define their HIBP [1]. For instance, the National Health Services NHS- in the United Kingdom covers almost all services

\footnotetext{
* Correspondence: arolyaee@gmail.com

${ }^{1}$ Health Equity ResearchCenter (HERC), Tehran University of Medical Sciences, Tehran, Iran

${ }^{4}$ National Institute of Health Research, Tehran University of Medical Sciences, No. 70, Bozorgmehr Ava., Vesal St., Keshavars Blvd, Tehran 1416833481, Iran Full list of author information is available at the end of the article
}

provided by public healthcare centres that are affiliated with the Department of Health [2, 3]. Whereas, the National Health Insurance- NHI- system in Germany develops the HIBP and restricts compensations to defined services that are included in the HIBP(s) [4]. Based on its health system, each country has its own mechanism of priority setting for policy coverage, through which a list(s) of services that are covered by the health insurance, so-called $\operatorname{HIBP}(\mathrm{s})$, is developed $[5,6]$.

By definition, developing a HIBP involves prioritization of healthcare services based on pre-defined indicators, 
during which, economic, clinical, and socio- political factors are considered [7]. Cost-effective and efficient development of a HIBP may face many challenges, particularly in the context of low and middle-income countries (LMICs). Similar to other settings, Iran's health system has been facing a series of challenges in developing and implementing appropriate HIBP, i.e., lack of shared perspectives among policy-makers, insufficient transparent prioritizing criteria, ambiguous and unclear organizational structures and unsustainable resources $[8,9]$. The Iranian Supreme Council of Health Insurance (ISCHI) is in charge of the process of decision-making for inclusion of a specific healthcare service into the basic insurance package. Conventionally, such decisions have been taken based on the bargaining power of various parties attending the ISCHI's meetings. For instance, the insurance corporations mainly take into account the financial burden of services [10].

Developing a HIBP is politically hierarchical and largely contextual, which is associated with the health system structure, available budget and technical capacity of the stakeholders [4]. Hence, no universal method exists to fit all health systems. This study aims to investigate the policy processes of developing and implementing the HIBP in Iran. We will propose evidence-informed policy options to increase the efficiency and cost-effectiveness of the current HIBP. Using policy process (as one of the four dimensions of policy: content, process, stakeholders, and content) analysis, this article attempts to answer the following questions: how to identify problems that are related to the development and implementation of the HIBP; who is engaged in the policy development process; how to develop a HIBPrelated policy; how to formalize policies that are related to the HIBP; how to implement these policies (HIBP development, making decisions process of HIBP); and finally, how to evaluate the HIBP in use.

\section{Setting}

Iran's health system is among very few that have merged medical education into service delivery. The Ministry of Health and Medical Education (MOHME) holds the stewardship of health system in Iran [11]. Enjoying an extensive network of over 60 universities of medical sciences (UMSs) across 31 provinces, the MOHME adminsters planning, service delivery, education, medicines' supply and research in Iran.society. Health system finacing is mixed and mainly provided through public expenditure $(51 \%)$. Social health insurance organizations pay for outpatient, inpatient and diagnostic services to about $90 \%$ of Iran's population. Although the major payment mechanism is Fee for Service (FFS), capitation is also used at the Primary Health Care (PHC) level, where 99 services, 436 medicines and 48 laboratory services are provided. Besides, at the second and third levels of healthcare provision, mainly specialized hospitals, 3685 services, 2210 medicines, 404 consumables, 796 laboratory services, and 709 medical imaging services are covered. The ISCHI, affiliated to the MOHME, is responsible for strategic purchasing of health services.

\section{Methods}

This is a qualitative research. We used both retrospective (policy analysis) and prospective (analysis for policy) approaches to investigate the policy-making process of the HIBP in Iran. "Policy analysis" refers to investigatation and analysis of past and current policies. "Analysis for policy" intends to identify appropriate policy options to address a challenge and improve policy [12]. Data collection and anlysis were conducted in two consecutive phases from February 2014 until October 2016. Conceptual freamwork of stydy is provided in Fig. 1.

\section{Phase 1: retrospective policy process analysis of HIBP}

We investigated four dimensions of the policy process: agenda-setting, policy development, policy implementation, and evaluation. Our main method for data collection was face-to-face semi-structured interviews with purposefully identified experts (Appendix 1). The participants were senior managers of the MOHME, the Ministry of Cooperatives, Labor, and Social Welfare (MOCLSW), members of health insurance organizations and the ISCHI as well as informant academics in health financing, health insurance and health economics. Interviews were continued until we reached data saturation, when 25 expert were interviewed. In fact, in the last interviews, no new data was added to the study, so we concluded that the data was saturated. No one refused to participate or dropped out from interviews and we did not repeat any interviews.

We used a literature-based and tailored interview guide (Appendix 2). All interviews took place in the interviewees' workplaces. The following issues were investigated during the interviews: how development of a HIBP was included in the MOHME agenda? How HIBP -related policies were developed (or are being developed)? The extent to which the HIBP development was evidence-based? What mechanisms were used to attract policy-makers' attention to the HIBP -related problems? How HIBP -related policies are being implemented? Is there an evaluation and revision process for the HIBP? What instruments and solutions were used for revising the HIBP?

We also used documents review to collect data, including laws, instructions, and contents of various protocols that were related to the HIBP. We also developed an information worksheet to collect and categorize legal documents (Appendix 3) and to prepare them for thematic analysis. 
Process analysis of HIBP

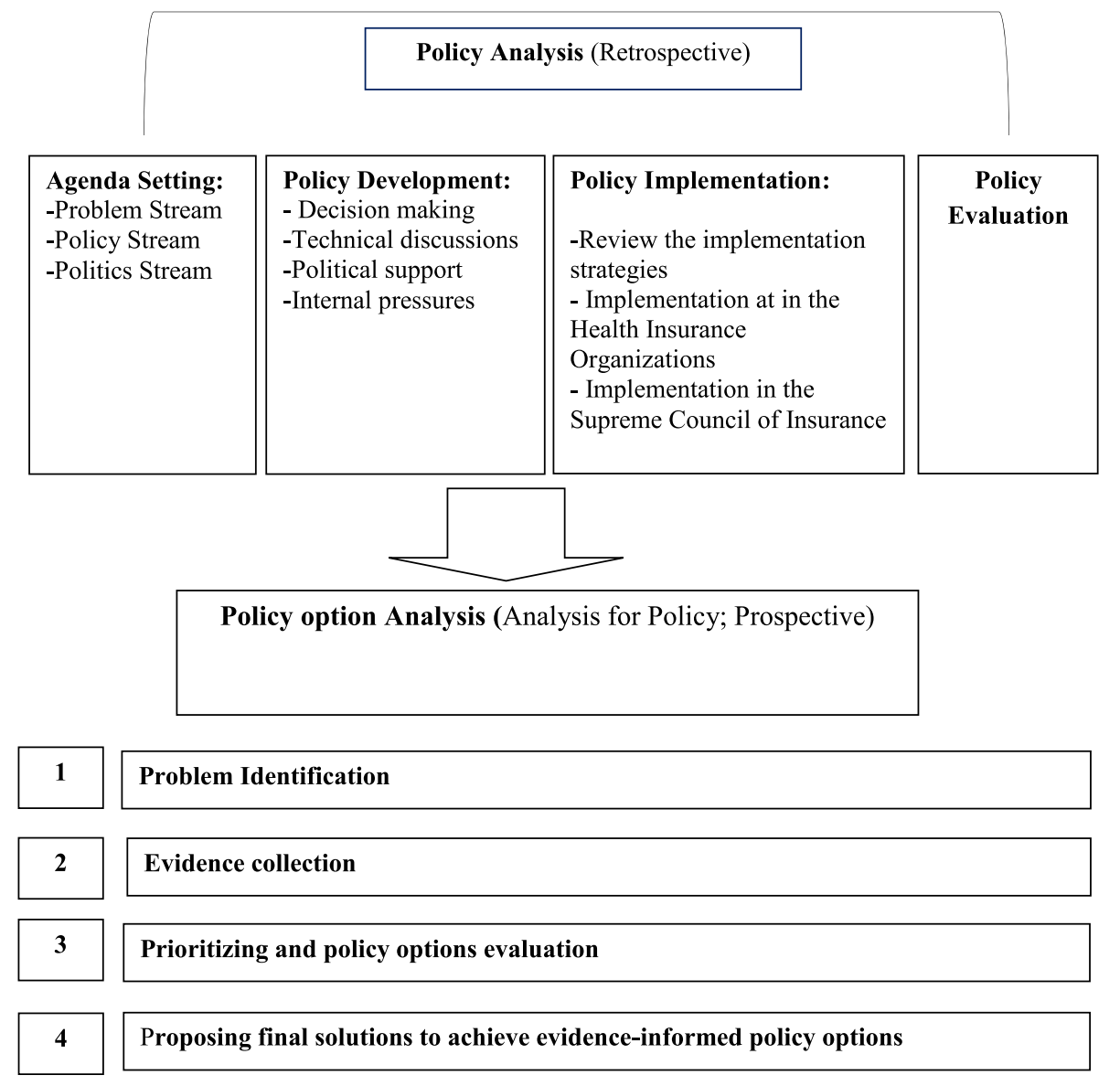

Fig. 1 Conceptual framework of policy process analysis of HIBP in Iran

In addition, one of authors (EM) participated in five meetings of the ISCHI, $15 \mathrm{~h}$ in total, to directly observe the decision-making process, stakeholders' engagement and their influences. All discussions and the researcher's perceptions were recorded.

We recorded all interviews and observations and transcribed verbatim. To ensure the accuracy of statements, we sent some transcripts to the interviewees and asked them for clarification, if necessary. Besides, relevant documents were categorized using the Microsoft Word software. An inductive thematic content analysis approach was used to analyze the data (Eloo 2007) and to categorize themes, MAXQDA.11 software was used to assist data management. AO and EM analyzed the data separately to assure the validity of the qualitative analysis.

\section{Phase 2: prospective policy-options analysis}

We followed a four steps policy analysis model [13] to draw evidence-informed policy options about the issues and challenges of developing the HIBP:
1. Problem identification: The finding of phase one were used to identify and list the issues and challenges of each dimension.

2. Evidence collection: We collected scientific evidence for each identified issue through the following methods: comprehensive review of valid databases; experts' opinions that were extracted from interviews; rationales extracted from investigating process; document review, and participating in ISCHI meetings. To search databases, MESH and Freetexts approaches were used. For this purpose, the most important medical electronic databases including the Cochrane, Pubmed, and Scopus were searched (2000-March 2016).

3. Prioritizing and evaluating policy options: after collecting evidence and primary development of policy options, a panel of professionals was convened to prioritize the policy options. A checklist which contained policy options (in the rows) and criteria (in the columns) was developed 
to obtain experts' opinions. All identified options were evaluated in terms of feasibility and necessity. The participants were asked to rate each option on a Likert scale ranged from 1 (the worst) to 10 (the best) (Appendix 4).

4. Final proposed solutions to achieve evidenceinformed and prioritized policy options: Experts' opinions were analyzed based on specified criteria. The data from the previous phase were analyzed using the Simple Additive Weighting (SAW) method. Therefore, the total score of each policy option was calculated by multiplying the comparable rating for each criterion by the weight assigned to the criteria and then summing these values for all criteria. Data were analyzed using the Microsoft Excel software. Finally, we developed a summary of final solutions in the form of policy options.

\section{Results}

In this section, first, we present findings of the retrospective qualitative analysis of the HIBP policies, followed by the results of policy options analysis.

Four main issues (i.e. agenda setting, policy development, policy implementation, and evaluation), 10 themes, and 78 sub-themes were identified (Table 1).

1. Agenda setting: To identify issues related to the Problem stream, Politics stream and Policies stream, the Kingdon multistream model was used [14]. Besides, 12 extra sub-themes were identified.

\section{- Problem stream}

The epidemiological transition fueled the constant increasing of demand for healthcare services, which led into spiraling health expenditures, which in turn revealed the importance of developing a HIBP. During the past four decades, a series of policies are developed and implemented in Iran that indicate the necessity of developing a basic health insurance package (e.g. the NHI Act of 1995, Supreme's leader mega policies for health, and instruction of strategic purchasing):

"Resource scarcity has always been an important problem for HIBP and, therefore, insurance organization always try to avoid implementing the HIBP ..." (R 12).

\section{- Policy stream}

Until now, no practical policy or scientific method is developed to design the implementation path of macro policies related to the HIBP in Iran. Issues such as lack of scientific criteria or evidence to develop or revise the HIBP and ignoring the epidemiological transition led into exacerbation of this problem:

"Currently, our problem is that we mistakenly consider the HIBP as strategic purchasing, but it must be mentioned which services are covered, based on what evidences and for whom, and why this package should be bought, what criteria should be used, I mean, why a service should be included in the HIBP" (R 26).

\section{- Politics stream}

In addition to political supports to HIBP that were endorsed by the sequential National Development Plans (NDPs), the Supreme leader's mega policies for health (2013) were a turning point in providing political support for the HIBP. The mega policies attracted more attention to the health sector and led to allcation of extra funds towards the health sector:

"In the eleventh government, government attention to the health sector problems and challenges significantly increased and continues" (R 11).

Our investigation showed that HIBP -related policies have always been developing, but the three streams of problem, policy, and politics never came together. Inadequate systematic revisions and approaches to the HIBP resulted in insufficient growth of policies stream, which in turn prevented the policy window to become fully open.

2. Policy development: two main themes (stewardship of policy making, and method and trend of decision-making) and 15 sub-themes were identified.

\section{- Stewardship of the policy-making}

We identified 65 documents containing various policies that were, directly or indirectly, related to the HIBP. The most obvious one was Article 29 of the constitution, which endorses social security as a right for all citizens:

"Having social security, in terms of retirement, unemployment, elderly, inability to work, orphanage, 


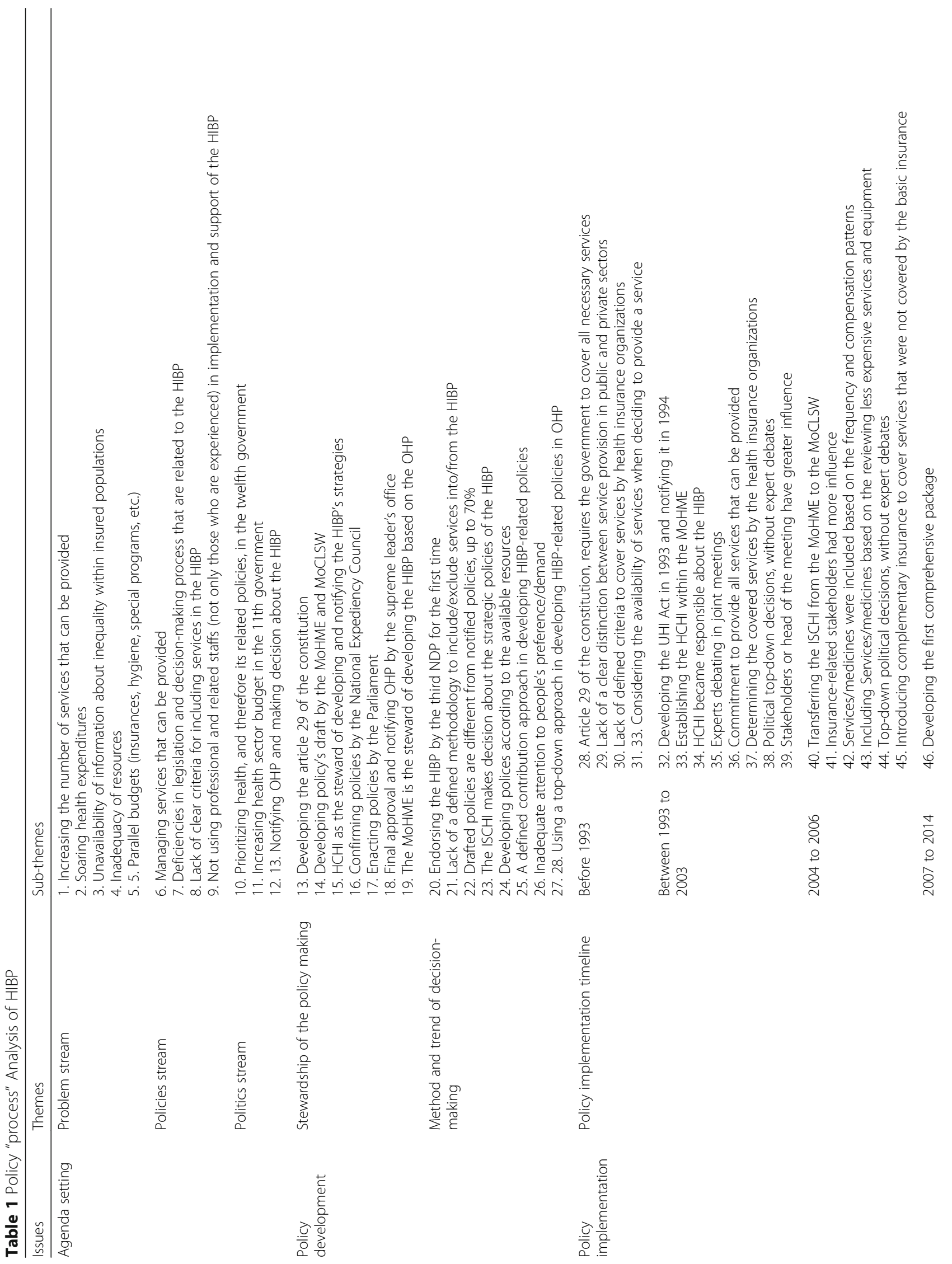




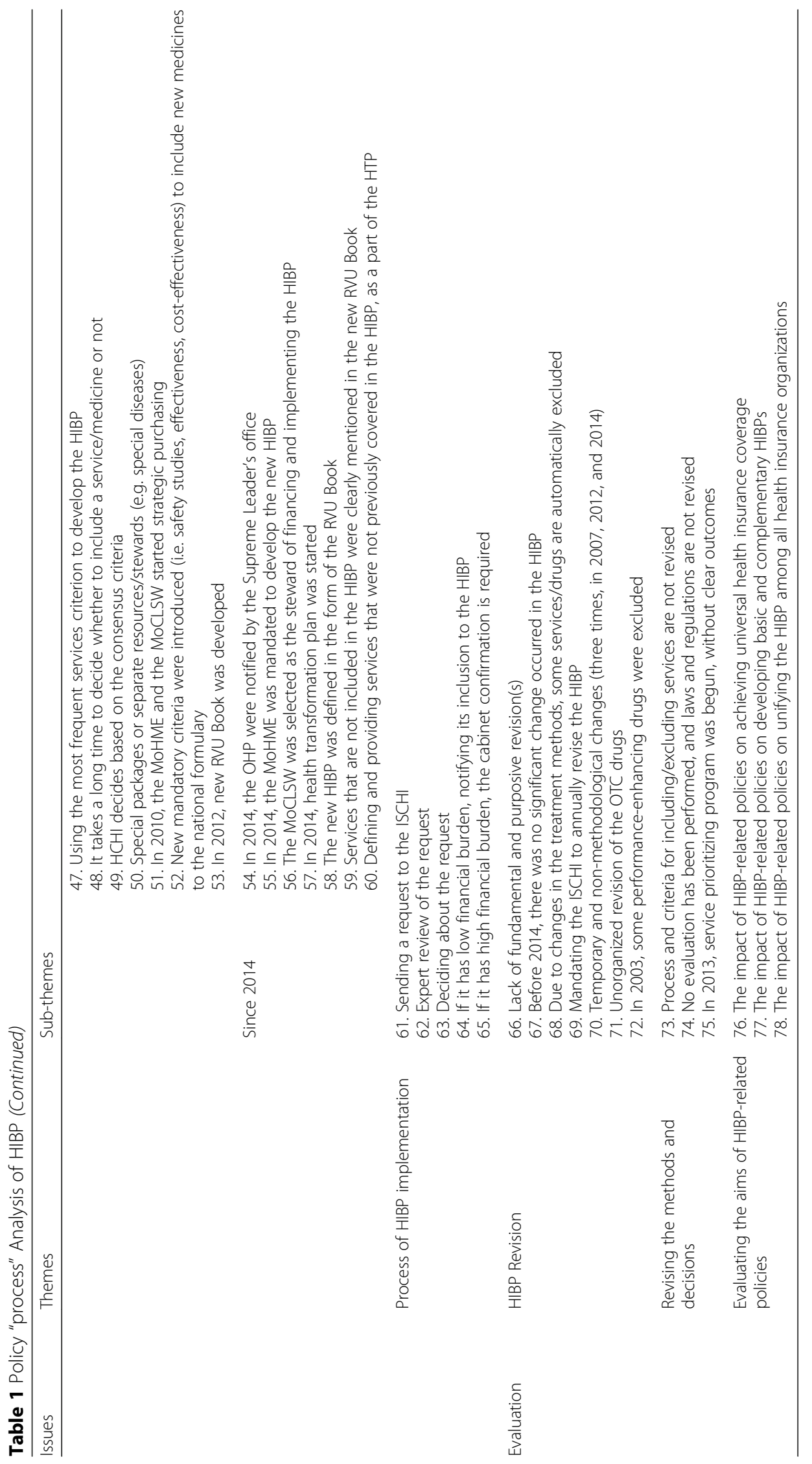


financial needs, accidents, health-care services and medical care, is a universal right for all Iranians" (Article 29 of the constitution).

The MOHME is in charge of drafting health sector policies, while the MOCLSW contributes to developing the draft policies related to the HIBP. The MOHME is also responsible to get the policy approval in liaison with four levels: The ISCHI, the cabinet, parliament, and supreme leader's office.

\section{- Methods and trends of decision-making}

The 3rd National Development Plan (NDP) of Iran endorsed health insurance, health system financing and HIBP -related issues for the first time, which were repeated in the next NDPs. Nevertheless, no organized decision-making process was designed to implement such policies. Consensus-making by officials and policy-makers (traditional negotiation style) was used to define the HIBP, where bargaining power had (and still has) an important role in influencing the decisions. The lack of transparency resulted in weak stewardship for HIBP-related policies:

"A serious problem occurs in the system ... because of the bargaining power of some policy-makers, some services won't be included in the HIBP, while some unnecessary services are included, and it's a serious problem in IHS" (R 6).

3. Policy implementation: two main themes (policy implementation timeline and the process of HIBP implementation), plus 38 subthemes were identified here.

\section{- Policy implementation timeline}

On the basis of the changes in the content of the benefit package, decision-making method, and the stewardship of decision-making, the implementation and revisions of HIBP-related policies can be categorized into five periods: before 1993, 1994 to 2003, 2004 to 2006, 2007 to 2014, and after 2014. Before 1993 and the enactment of the Universal Health Insurance Act (UHIA), health laws were mainly focused on service coverage, whilst there was no comprehensive document to define the services that each health insurance organization should cover.

In 1993, by the enactment of the UHIA and establishment of the ISCHI, coherence of health insurance policies increased. The ISCHI was initially affiliated to the MOHME, while most of its members came from various health insurance organizations, plus the Iranian Medical Association (IMA). The ISCHI was responsible to make decisions about inclusion and/or exclusion of medical services into the HIBP. No debate among experts took place to make such decisions.

In 2004, the ISCHI was transferred to the newly established MOCLSW. During this period, the decision criteria to include new services were frequency and utilization patterns, which were based on the insurance organizations' reports. In 2007, the biggest change occurred in the HIBP governance, when the ISCHI began to uniform the HIBP among all health insurance organizations. All covered services were published in a book, called "basic package of 2007". After the enactment of the fifth NDP in 2012, the MOCLSW started a new reform to evaluate the HIBP. Although those measures were based on a scientific methodology -called "new HIBP"-, the previous package was enacted in reality.

The Health Transformation Plan (HTP) that was implemented in 2014 also affected the HIBP through revising the medical tariffs as well as the new Relative Value Unit (RVU) Book. In this book, all services that are available in Iran's health system, i.e. procedures, surgeries, imaging, and laboratories are listed; those services which did not cover by any insurance organizations, are marked with an asterisk (").

“...By 2013, the book of RVU was published. This book includes all new and old health services. It was considered as a HIBP revision, the book was intended to revise the tariff but In fact, there was some kind of review HIBP..." (R 19)

\section{- The process of the HIBP implementation}

Since 1993, all decisions about including and/or excluding a service within the HIBP are made by the ISCHI, with the participation of related stakeholders. When a new service is proposed to be included in the HIBP, the ISCHI invites various stakeholders (i.e. permanent members of the HHIC, and representatives of the MOHME, health insurance organizations, and the IMA as well as other members from professional associations), to attend in a meeting and to discuss the agenda. The process and methods of holding these meetings have not changed significantly ever since, with consensus building among members as the dominant method for making decisions. The bargaining power of health insurance organizations is mainly focused on the financial burden of services, while professional associations may attempt to exaggerate the importance of proposed services. Except for a few cases, no specific criteria and/or method (e.g. cost-effectiveness studies, guidelines) is 
used to make such decisions. As a rule, several meetings (in some cases it may take several years) are held to make a decision. Services with a high financial burden should be confirmed by the cabinet:

"In some cases, health insurance organizations propose a service, all propositions, either from the MoHME or MoCLSW, send to the HCHI for expert analysis. There is a waiting list. Representatives from the different organizations as well as MoHME and MoCLSW debate. If consensus is on its inclusion, the cabined must confirm the decision" (R 3).

4. Evaluation of HIBP-related policies: evaluation refers to the investigation of whether the goals of the policies were achieved and whether an implementation gap exists. Three main themes were identified: revision of the HIBP, revising the methods and decisions, and evaluating the aims of HIBP -related policies. 13 sub-themes were also identified.

\section{- HIBP's revision}

Since 1993, any revision in the HIBP has been mainly focused on creating a more coherent and evidence-based package. In some cases (e.g. in 2007, 2012, and 2014), revisions were temporary and without a defined methodology. The findings showed that no purposive and fundamental revision was conducted. We identified a series of reactional, vs proactive, changes in the content of HIBP. Rarely, in less than 10 cases, an emerging need led to inclusion or exclusion of some medicines, medical equipment, and services into/from the HIBP:

"It's more than 30-years that we have the HIBP, but there is not a defined method for including a new and better service. Whether it should replace the older service or not"(R 4).

Exclusion of over-the-counter (OTC) drugs was one of the main recent changes. In 2012, an expert panel was established for exclusion of OTC drugs from the HIBP and allocating the released funds for medicines related to special diseases.

\section{- Revising the methods and decisions}

Processes that are related to the inclusion and/or exclusion of services/drugs into/from the HIBP are not evaluated and revised yet. Meanwhile, due to technological advances or the introduction of lower-cost interventions, revisions deem necessary, some committed HIBP are not covered:

"We never tried to revise the covered services. As well, we never tried to evaluate the HIBP” (R 12).

\section{- Evaluating the aims of HIBP-related policies}

Despite the legislator's emphasis on the annual revision of necessary commitments by health insurance organizations, this is only available for medicines packages and its execution was not regular. In 2007, Article 3 of the comprehensive welfare and social security system Act resulted in a big improvement towards a more transparent decision making about the HIBP and increasing the awareness about insurance services. According to the RVU Book (2015), coverage of inpatient and Para-clinic services included in the HIBP was 88 and 89.9\%, respectively. Moreover, the National Health Accounts (NHA) (2013) showed that financial burden of uncovered services, those excluded from the HIBP, was only $6 \%$.

\section{Limitations and solutions}

After analyzing the interviews, fourteen challenges and constrains regarding the HIBP policies were identified. A summary of identified issues and problems is described in Table 2; it is worth noting that there are no priorities in the identified limitations.

11 solutions and 25 policy options were extracted, at least two policy options per each solution. Consequently, based on the pros and cons of each one as well as appropriateness and feasibility criteria, they were prioritized by an expert panel (Table 3 ).

Table 2 Limitations and problems of the HIBP policy process

Limitations and issues that can be investigated

- Lack of clear criteria to include services into the HIBP

- Not considering the epidemiological transitions to increase the

effectiveness of included services.

- Scientific evidences were not adequately used

- Health Technology Assessment (HTA) studies were not used

- Bargaining power had an important role in the ISCHI decisions

- The extensive HIBP list regardless of the priorities and costs

- Policies on HIBP and the strategic purchasing were not implemented

- Cultural, social and economic issues were not considered

- Passive performance of health insurance organizations to include new proposed services within the HIBP

- Lack of revision and evaluation systems

- OTC drugs are included in the HIBP

- Unproportioned percentage of the health expenditures are created

by a small percentage of patients

- Development and implementation of programs and policies are not permanent

- Inadequate resources 


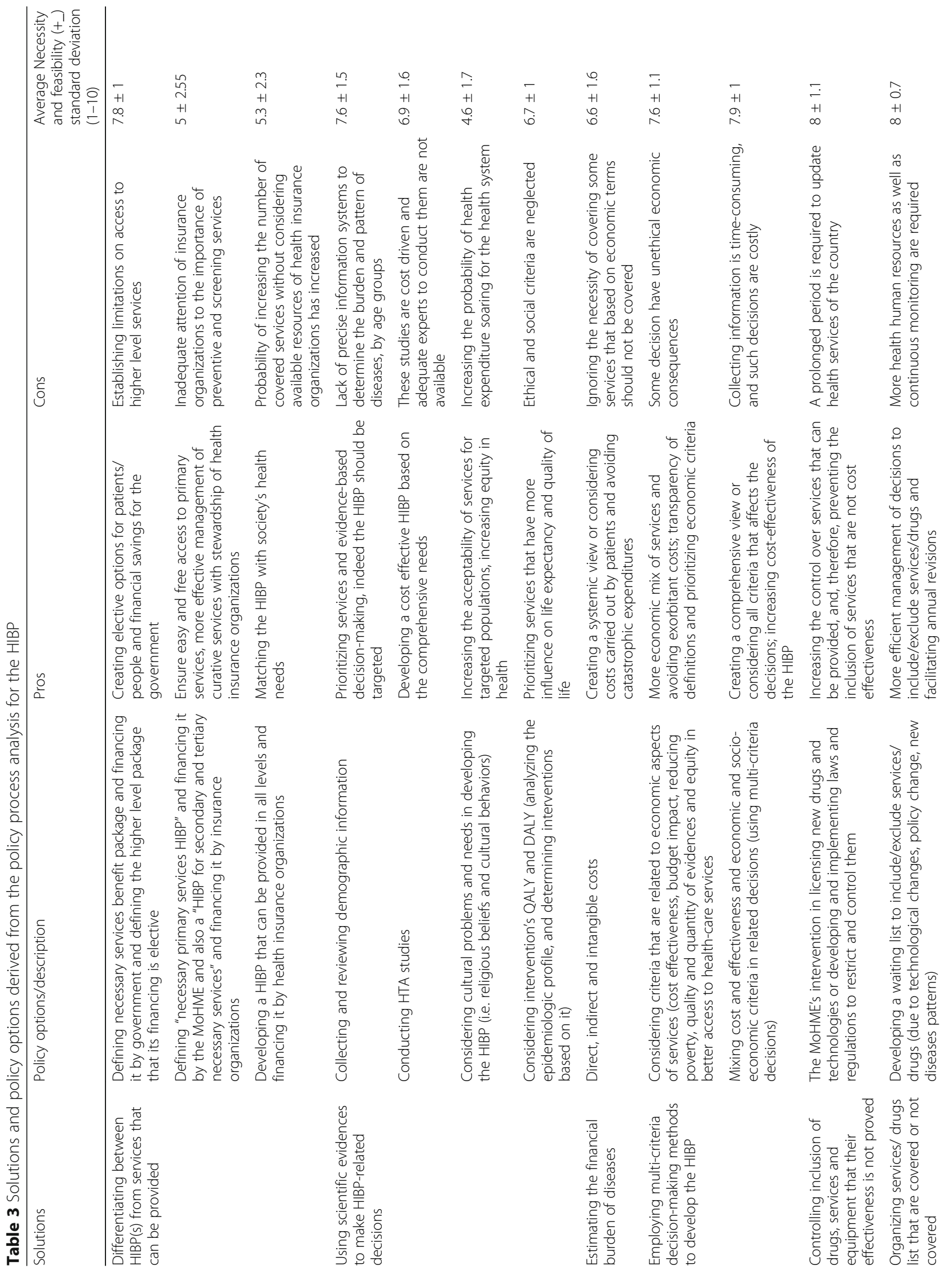




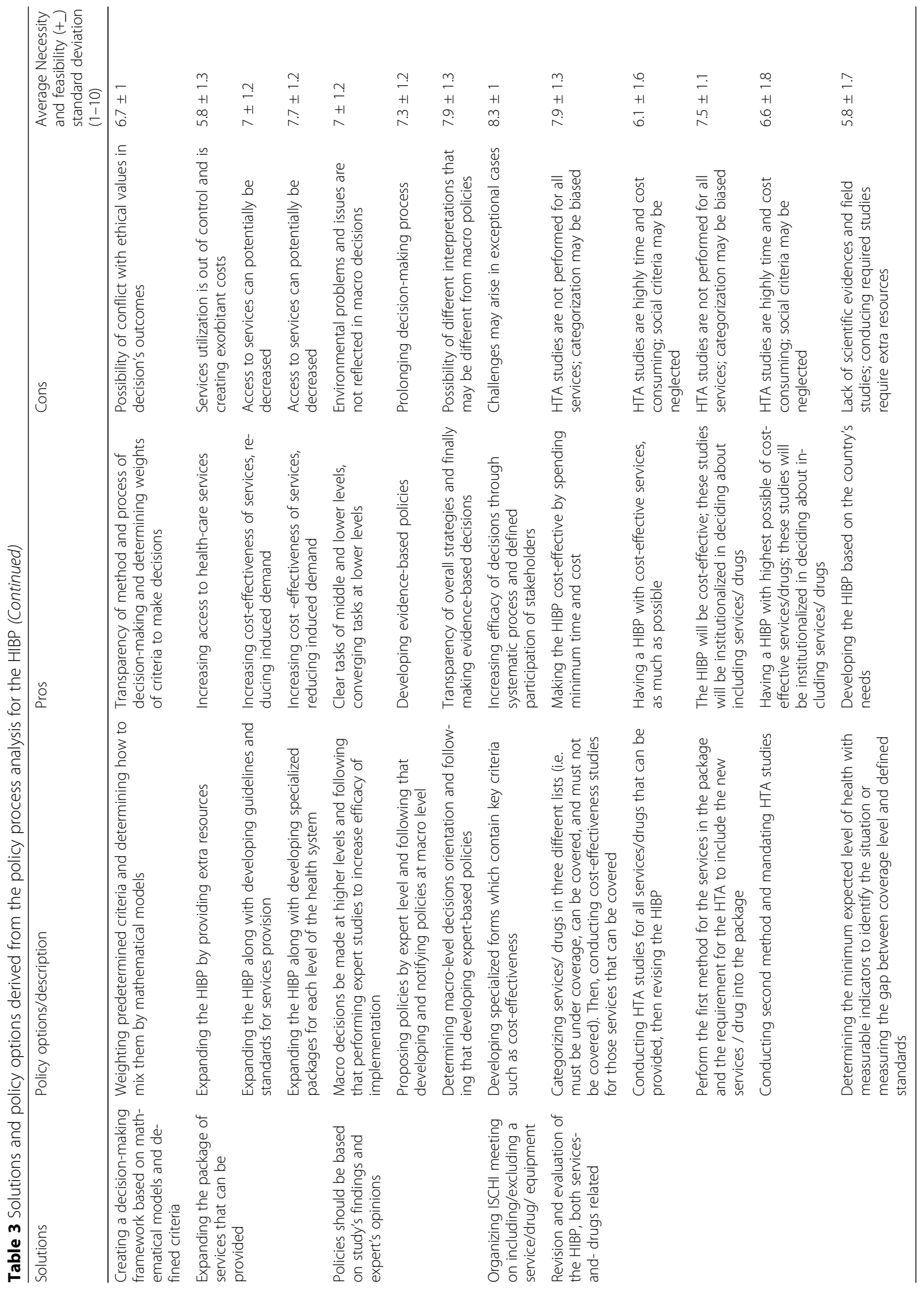




\section{Discussion}

We investigated the policy process (i.e. agenda-setting, development, implementation, and evaluation) analysis for the HIBP in Iran. We found that various stakeholders developed different policies with different contents that had a defined algorithm. Meanwhile, different forces influenced the policy-making process. Such a mechanism has resulted in an idiosyncratic way of policy-making and defining the HIBP in Iran. At the macro level, the amount and source of financing are the main criteria to make such decisions.

According to the results, the main obstacle for inclusion or exclusion of services is lack of evidenceinformed decision making. So far, several reforms have been conducted to revise the HIBP in Iran, the most important one was the third phase of the HTP that contained the revision of "Relative Values of the Diagnosis and Treatment Services". It covers numerous diagnostic and surgery services that previously were not covered by basic insurance organizations. In the "Package for Reducing the Deduction for Diagnostic and Curative Services", the co-payments for inpatient services were reduced from $10 \%$ (and informally about 30\%) to $6 \%$. This was accompanied by obliging the hospitals to provide all necessary equipment and supplies for patients within the hospitals. Implementing these policies caused substantial decline in absolute out-of-pocket payments for inpatient services. Nonetheless, further reforms are needed to improve strategic purchasing in Iran.

Our identified solutions and policy options showed that experts considered managing the inclusion of drugs, services, and equipment, organizing services/drugs lists, using scientific evidence to make HIBP -related decisions, and organizing ISCHI meeting on inclusion/exclusion of various items more than any other solution to define the HIBP. It seems that structural modifications are needed more than other changes to improve the HIBP.

The experience of other countries show the macro policy criteria, i.e. qualified services and diseases to be covered, ways to cover various age groups and financing methods, by both insurance organization and the government, as the main considerations in designing the benefit package [15]. In France, for example, an independent organization has been established to regulate, facilitate and enhance the transparency of the HIBP and organize providers' compensation. A new treatment will only be accepted if it is proved to have higher benefits (with the same level of costs) or lower costs (with the same level of benefits) $[7,16]$. It seems that the debates around developing policies and changing the steward of developing the HIBP are mostly focused on the source of financing, while adequate attention has not been paid to how to develop the HIBP with targeting diseases/ individuals.
Several studies have investigated the concept of HIBP, its challenges and limitations. Studies performed in Colombia and Philippine used the instrument developed by WHO to assess the strategic purchasing of health services. In Colombia, the revision of the benefit package was reported to be based on a transparent, scientifictechnical and participatory process [17]. Similar to Iran, in the Philippine, there was no benefit expansion plan or strategy. Hence, all the existing benefit packages of the Philippine might be crafted and approached in an unstandardized and ad hoc environment [18].

Another study conducted in Iran reported that one of the main challenges in the SP is the type of services and goods purchased (what to purchase?). In addition, they identified several problems in the present benefit package, i.e. inappropriate information systems, unsuitable mechanisms and criteria to select included services, and inappropriate trustees to decide about the service package. Simple interventions (i.e. prioritizing the services, determining the effectiveness, efficiency and safety of services, and definition of the criteria for reviewing the package as well as assessing the feasibility of introducing some preventive services to the package) can make the HIBP more effective [19].

The decision-making process to design HIBP is based on reliable evidence and through scientific methods in many countries [20]. Our findings revealed that the HIBP is mostly defined based on negotiating with stakeholders in Iran, while the HIBP revisions were mostly temporal and non-systematic. Evidence shows the need for systematic annual or at least biannual evaluations for substituting less effective services/drugs with more effective ones. This can increase the quality of provided services as well as efficiency. Thailand uses a four-step mechanism to make decisions that are related to include a service into the HIBP. They use the criteria as follows: the number of patients who suffer from the disease, severity, cost-effectiveness of intervention(s), types of available services, the economic impact on households, and ethical and equity issues in evaluating the package [21]. Norway and France use below criteria to evaluate a service: cost-effectiveness, personal benefits and severity of the disease [22].

\section{Policy recommendation}

Here, following prioritization and evaluation of political options, we recommend:

\section{- Creating different packaged based on the type of services}

A HIBP should only contain 'necessary services', while other services can be financed through complementary insurance or users' direct contribution. 


\section{- Evidence-based decisions for the content of HIBP}

To incorporate evidence-informed decision-making criteria, i.e. Health Technology Assessment (HTA) and cost-effectiveness analysis, into the process of the ISCHI meetings, HIBP-related decisions should be based on scientific evidence, precise demographic information (separated by age groups, special needs of each age group, and defined targeted package according to such information) as well as considering a combination of cost-effectiveness and socio-economic conditions of the country (using multi-criteria decision-making to include services) in the frame of using multi-criteria decisions.

To control provision of services and procedures, a series of interventions and regulations should be introduced to restrict the inclusion of new drugs and technologies to the most cost-effective ones.

\section{- Periodical Revision of the HIBP}

In line with periodic evaluation and to increase the organization of services/drugs lists that are covered, a waiting list needs to be developed for those services/ drugs that are under review to be included and those that are about to be excluded,. To increase the capacity of the health system for expansion of service provision based on the health equity and promoting Universal Health Coverage (UHC), new guidelines and standards should be developed for revising the HIBP. For instance, the coverage should be restricted to those who are eligible. Moreover, specialized HIBPs for each level of service provision based on the age groups and disease categories should be defined.

For revision and evaluation of the current HIBP, we suggest categorizing services and drugs into three different lists (i.e. must be covered, must not be covered, and can be covered) based on the cost-effectiveness, budget impact, safety, and availability of alternative services criteria as well as experts' and users' opinions. This can be galvanized by including the findings of HTA studies for the services that can be covered.

\section{Strengths and limitations}

To the best of our knowledge, this is the first deep and extensive study for analyzing the HIBP policies in Iran, whose findings can respond to long-waiting questions of health policy-makers in this regard. The final solutions presented in this study are based on scientific and objective evidence that have been approved by the experts. However, our study had some limitations. We did not find a universal definition of a HIBP, and encountered discrepancies between scientific literature and the experience of different countries. We also faced some challenges in obtaining some documentation from different organizations, i.e. the executive instructions and the expired regulations that were not cited on the websites, due to which determining the effects of the HIBP implementation in achieving desired goals might be incomplete.

\section{Conclusions}

Given the limited resources and ever-increasing public demand for healthcare services, designing an evidencebased HIBP, which is in line with upstream policies, is crucial to reach and sustain UHC in Iran. This renders a systematic implementation process and appropriate ways to manage stakeholders' power and influence for minimizing the possibility of conflicts during the HIBP development. Equitable and quality healthcare with no one left behind is at the heart of UHC, which is in turn the center of sustainable health development. To reach UHC by 2025, as manifested by the MOHME, Iran has no choice but to implement substantial reforms into its pathway in designing evidence-informed health HIBP, i.e. but not limited to employing efficient financial, economic and political solutions, e.g. HTA. Unless the conventional method of negotiation and bargaining is replaced with robust, transparent, and culturally accepted ways of defining the HIBP, the healthcare system of Iran will face unsustainability in the provision of resources and public dissatisfaction, which may in turn endanger its pathway along with sustainable health development.

\section{Supplementary information}

Supplementary information accompanies this paper at https://doi.org/10. 1186/s12913-020-05592-W.

\section{Additional file 1.}

\section{Abbreviations}

HIBP: Health Insurance benefit Package; HTA: Health Technology Assessment; HTP: Health Transformation Plan; IMA: Iranian Medical Association; ISCHI: The Iranian Supreme Council of Health Insurance; MOCLSW: Ministry of Cooperatives, Labor, and Social Welfare; MOHME: Ministry of Health and Medical Education; NDPs: National Development Plans; NHA: National Health Accounts; NHI: National Health Insurance; OTC: Over-The-Counter;

PHC: Primary Health Care; RVU: Relative Value Unit; SAW: Simple Additive weighting; UHC: Universal Health Coverage; UHIA: Universal Health Insurance Act; UMSs: Universities of Medical Sciences

\section{Acknowledgements}

The authors acknowledge the Ministry of Health and Medical Education of Iran and Tehran University of Medical science, for providing the situation to participate in ISCHI meetings and coordinating interviews with experts.

\section{Authors' contributions}

$A O, A R$ and MR conceived the study and designed its method. EM the acquisition, analysis and interpretation of data with help from $A O$ for revision of the analytical method. All authors discussed the results and contributed to the final manuscript. EM and $\mathrm{AH}$ carried out the analytical experiment. EM, AT and S.GH wrote the manuscript. All authors contributed to the development and approved the final manuscript. AO is the guarantor. 


\section{Funding}

This research was funded by Tehran University of Medical science.

\section{Availability of data and materials}

The data of this study were raw data, which we access them by interview and report them in the paper. The datasets used and/or analyzed during the current study are available from the corresponding author on reasonable request.

\section{Ethics approval and consent to participate}

We had assured confidentiality of Topic Guide information. Given that there was no invasive intervention, verbal consent was obtained from interviewers at the beginning of the interview. Written consent was not necessary for this study because the name of the interviewee was not mentioned in the findings; it was just explained at the beginning of the interview to the interviewee that your point of view would be published anonymously and after the content analysis process. The current study is confirmed by the Ethical Committee of Tehran University of Medical Science (code: IR.TUMS.REC.1395.2517).

\section{Consent for publication}

Not Applicable.

\section{Competing interests}

There is no conflict of interests.

\section{Author details}

${ }^{1}$ Health Equity ResearchCenter (HERC), Tehran University of Medical Sciences, Tehran, Iran. ${ }^{2}$ Department of Health Management and Economics, School of Public Health, Tehran University of Medical Sciences, Tehran, Iran. ${ }^{3}$ Department of Global Health and Public Policy, School of Public Health, Tehran University of Medical Sciences, Tehran, Iran. ${ }^{4}$ National Institute of Health Research, Tehran University of Medical Sciences, No. 70, Bozorgmehr Ava., Vesal St., Keshavars Blvd, Tehran 1416833481, Iran. ${ }^{5}$ Information, Evidence and Research Department, Eastern Mediterranean Regional Office, World Health Organization, Cairo, Egypt. ${ }^{6}$ Health Insurance Organization of Iran, Tehran, Iran. ${ }^{7}$ Brandeis University, Waltham, MA, USA.

Received: 28 August 2019 Accepted: 28 July 2020

Published online: 06 August 2020

\section{References}

1. Olyaeemanesh A, Behzadifar M, Mousavinejhad N, Behzadifar M, Heydarvand S, Azari S, et al. Iran's health system transformation plan: a SWOT analysis. Med J Islam Repub Iran. 2018;32:39.

2. Bevan G, Hood C. Health policy: have targets improved performance in the English NHS? BMJ: British Medical Journal. 2006;332(7538):419.

3. Mohamadi E, Tabatabaei SM, Olyaeemanesh A, Sagha SF, Zanganeh M, Davari $\mathrm{M}$, et al. Coverage Decision-Making for Orthopedics Interventions in the Health Transformation Program in Iran: A Multiple Criteria Decision Analysis (MCDA). Shiraz E-Medical Journal. 2016;17(12).

4. Saltman R, Rico A, Boerma W. Social health insurance systems in western Europe: McGraw-hill education (UK); 2004

5. Oliver A, editor Health care priority setting: implications for health inequalities. Proceedings from a meeting of the Health Equity Network Londres, The Nuffield Trust; 2003.

6. Segal $\mathrm{L}$, Chen Y. Priority setting models for health. Report to the population health division West Heidelberg. Centre for Health Program Evaluation, februari: Australia; 2001.

7. Teerawattananon Y, Kingkaew P, Koopitakkajorn T, Youngkong S, Tritasavit $\mathrm{N}$, Srisuwan $\mathrm{P}$, et al. Development of a health screening package under the universal health coverage: the role of health technology assessment. Health Econ. 2016:25(S1):162-78.

8. Bazyar M, Rashidian A, Kane S, Mahdavi MRV, Sari AA, Doshmangir L. Policy options to reduce fragmentation in the pooling of health insurance funds in Iran. Int J Health Policy Manag. 2016;5(4):253.

9. Mohamadi E, Olyaeemanesh A, Rashidian A, Hassanzadeh A, Razavi M, Foroushani AR. Stakeholders analysis of health insurance benefit package policy in iran. Health Scope. 2017;7(2).

10. Mohamadi E, Olyaeemanesh A, Rashidian A, FOROUSHANI AR, Hassanzadeh A, Hasumi M, et al. Measuring public preferences for changes in the health
Insur-ance benefit package policies in Iran: a survey approach. Iran J Public Health. 2020:49(5):940-8.

11. Danaei G, Farzadfar F, Kelishadi R. Rashidian A. Ahmadnia S, et al. Iran in transition. The Lancet: Rouhani OM; 2019.

12. Buse K, Mays N, Walt G. Making health policy: McGraw-hill education (UK); 2012.

13. Weimer DL, Vining AR. Policy analysis: concepts and practice: Taylor \& Francis; 2017.

14. Kingdon JW. A model of agenda-setting, with applications. L Rev MSU-DCL. 2001;331.

15. Meessen B, Hercot D, Noirhomme M, Ridde V, Tibouti A, Tashobya CK, et al. Removing user fees in the health sector: a review of policy processes in six sub-Saharan African countries. Health policy and planning. 2011;26(suppl_2): ii16-ii29.

16. Rochaix L, Xerri B. National Authority for health: France: Commonwealth Fund; 2009.

17. Rivillas JC, Ortiz D, Henao AC. Rapid assessment of the purchasing arrangements in health system of Colombia. F1000Research. 2018;7.

18. Picazo OF, Ulep VGT, Pantig IM, Ho BL. A critical analysis of purchasing of health services in the Philippines: a case study of PhilHealth. PIDS Discussion Paper Series, 2015.

19. Dehnavieh R, Sirizi MJ, Mehrolhassani MH, Kalantari A. Strategic purchasing of healthcare services in developing countries: a new approach is required. Iran J Public Health. 2016:45(9):1241.

20. Greß S, Niebuhr D, Rothgang H, Wasem J. Criteria and procedures for determining benefit packages in health care: a comparative perspective. Health Policy. 2005;73(1):78-91

21. Youngkong S, Baltussen R, Tantivess S, Mohara A, Teerawattananon Y. Multicriteria decision analysis for including health interventions in the universal health coverage benefit package in Thailand. Value Health. 2012; 15(6):961-70.

22. Defechereux T, Paolucci F, Mirelman A, Youngkong S, Botten G, Hagen TP, et al. Health care priority setting in Norway a multicriteria decision analysis. BMC Health Serv Res. 2012;12(1):39.

\section{Publisher's Note}

Springer Nature remains neutral with regard to jurisdictional claims in published maps and institutional affiliations.
Ready to submit your research? Choose BMC and benefit from:

- fast, convenient online submission

- thorough peer review by experienced researchers in your field

- rapid publication on acceptance

- support for research data, including large and complex data types

- gold Open Access which fosters wider collaboration and increased citations

- maximum visibility for your research: over $100 \mathrm{M}$ website views per year

At $\mathrm{BMC}$, research is always in progress.

Learn more biomedcentral.com/submissions 